\title{
eNOS activation and NO function: Differential control of steroidogenesis by nitric oxide and its adaptation with hypoxia
}

\author{
Charles A Ducsay and Dean A Myers ${ }^{1}$ \\ Center for Perinatal Biology, Loma Linda University School of Medicine, Loma Linda, California 92350, USA \\ ${ }^{1}$ Department of Obstetrics and Gynecology, University of Oklahoma Health Sciences Center, Oklahoma City, Oklahoma 73190, USA \\ (Correspondence should be addressed to C A Ducsay; Email: cducsay@llu.edu)
}

\begin{abstract}
Nitric oxide (NO) plays a role in a wide range of physiological processes. Aside from its widely studied function in the regulation of vascular function, $\mathrm{NO}$ has been shown to impact steroidogenesis in a number of different tissues. The goal of this review is to explore the effects of $\mathrm{NO}$ on steroid production and further, to discern its source(s) and mechanism of action. Attention will be given to the
\end{abstract}

regulation of $\mathrm{NO}$ synthases in specific endocrine tissues including ovaries, testes, and adrenal glands. The effects of hypoxia on generation of $\mathrm{NO}$ and subsequent effects on steroid biosynthesis will also be examined. Finally, a potential model for the interaction of hypoxia on $\mathrm{NO}$ synthesis and steroid production is proposed.

Journal of Endocrinology (2011) 210, 259-269

\section{Introduction}

Nitric oxide (NO) is a diatomic free-radical gas involved in a number of physiologic processes (Moncada \& Palmer 1991, Moncada et al. 1991) and is synthesized from L-arginine by a family of NO synthases (NOS; Ignarro 2002). There are three isoforms including the constitutively expressed neuronal NOS (nNOS/NOS-I) and endothelial NOS (eNOS/NOS-III) and a third inducible isoform NOS (iNOS/NOS-II; see Daff (2010) for review). iNOS is $\mathrm{Ca}^{2+} /$ calmodulin independent while eNOS and nNOS are regulated by $\mathrm{Ca}^{2+}$ and calmodulin (Michel \& Feron 1997). In general, NO produced by eNOS and nNOS appears to regulate physiologic functions while iNOS tends to be involved in more pathophysiological situations.

The role of $\mathrm{NO}$ in the regulation of vascular function has been clearly defined (see Ignarro (2002) for review). Recently, it appears that this diatomic gas has profound inhibitory effects on steroidogenesis in a wide range of endocrine tissues and NOS are subject to regulation by hypoxia. As such, NO represents a potential mechanism for changes in steroidogenesis in response to hypoxia. This review will focus on the role of $\mathrm{NO}$ in the regulation of steroidogenesis and the potential interaction of NO production and hypoxia.

This paper is one of three papers that form part of a Thematic review section on eNOS activation and NO function. The Guest Editor for this section was Ian Bird, University of Wisconsin-Madison, USA.

\section{$\mathrm{NO}$ and steroidogenesis}

The initial rate-limiting step in steroidogenesis involves cholesterol transport to the inner mitochondrial membrane by steroidogenic acute regulatory protein (StAR) and its binding partner, peripheral benzodiazepine receptor. Within the mitochondria, StAR transfers cholesterol to CYP11A1 (P450 side-chain cleavage), which carries out a second rate-limiting step, conversion of cholesterol to pregnenolone (Pon et al. 1986, Arakane et al. 1997, Stocco 2001). NO has been clearly shown to have a profound effect on steroidogenesis in a wide range of endocrine tissues and CYP11A1 has been suggested as one potential target due to its fundamental role in steroidogenesis. Studies in multiple species and endocrine tissue types have demonstrated primarily an inhibition of steroid production by NO. The principal endocrine organs in which $\mathrm{NO}$ has been found to have an impact are the ovary, testes, and adrenal gland. The effects of NO on these tissues will be discussed separately below.

Ovary Using corpora lutea (CL) from pseudo-pregnant rabbits, Gobbetti et al. (1999) demonstrated that treatment with the NO donor nitroprusside resulted in a two- to fivefold decrease in progesterone production that was reversed with the NOS inhibitor $\mathrm{N}(\mathrm{G})$-nitro-L-arginine methyl ester (L-NAME). Furthermore, the luteolytic activity of PGF2 $\alpha$ was inhibited with L-NAME treatment, suggesting that NO may mediate prostaglandin-induced functional luteolysis. 
Additional studies in the rabbit also demonstrated that $\mathrm{NO}$ downregulates estradiol $\left(\mathrm{E}_{2}\right)$ biosynthesis during the follicular phase (Yamauchi et al. 1997). The same study further noted that NO also regulated prostaglandin synthesis, which in turn affected efficiency of follicular rupture.

In the rat ovary, iNOS and eNOS demonstrated distinct cell-specific expression patterns regulated differentially during follicular and luteal development (Jablonka-Shariff \& Olson 1997). In porcine CL, studies revealed that NO not only inhibited progesterone and $\mathrm{E}_{2}$ synthesis (Masuda et al. 1997, 2001) but also regulated steroidogenesis differently depending on the phase of follicular development. Using granulosa cells derived from both small $(<3 \mathrm{~mm})$ and medium $(3-5 \mathrm{~mm})$ follicles, they found that $\mathrm{NO}$ inhibited $\mathrm{E}_{2}$ production by directly inhibiting aromatase activity in granulosa cells from follicles at both levels of maturity. However, in the presence of gonadotropin, NOS inhibition with methyl arginine (L-NMMA) increased production of $\mathrm{E}_{2}$ and progesterone in granulosa cells, albeit to a lesser extent, from the less mature, smaller follicles than in the larger more mature follicles (Masuda et al. 2001). It was suggested that locally released NO in granulosa cells may serve a paracrine function by causing local vasodilatation and enhanced blood flow to the maturing follicle and CL. In contrast to earlier studies, Faes et al. (2009) found that $\mathrm{NO}$ positively regulated $\mathrm{E}_{2}$ synthesis via cGMP during the first $24 \mathrm{~h}$ of culture in bovine granulosa cells while it inhibited progesterone synthesis in a cGMP-independent manner. This is a surprising finding that was not fully explained. The most reasonable explanation for the seemingly contradictory results was the use of a chemically defined medium replacing BSA with polyvinyl alcohol.

More recent studies implicated an inverse relationship between ovarian NOS activity and synthesis of StAR (Srivastava et al. 2007). This laboratory previously found that alcohol intake during adolescence in rhesus monkeys suppressed $\mathrm{E}_{2}$ that, in turn, delayed development of regular menstrual cycles (Dees et al. 2000). With these data together, Srivastava et al. (2007) suggested that a combined action of alcohol enhancing ovarian NOS while suppressing StAR expression contributed to these abnormalities. The mechanisms of NO suppression of steroidogenic activity will be discussed later in this review.

Testes The earliest studies to recognize the potential effect of $\mathrm{NO}$ on steroidogenesis in the testes examined the effect of the NOS inhibitor L-NAME on serum and interstitial testosterone levels (Adams et al. 1992). Inhibition of NOS activity resulted in a significant enhancement of testosterone concentrations without affecting prolactin or LH levels. The authors concluded that NO exerted an inhibitory effect on testicular steroidogenesis. However, the specific site of action or mechanism was not defined. In an effort to determine the potential mechanism and site of action of NO in the testes, Welch et al. (1995) treated enriched Leydig cells in vitro with L-NMMA or L-NAME. This resulted in an increase in rat Leydig cell testosterone synthesis with a concomitant decrease in cGMP accumulation in Leydig cell-enriched cultures. D-NMMA, the inactive enantiomer however, had no effect on testosterone levels. Furthermore, the observed inhibition of testosterone was not associated with a change in specific human chorionic gonadotropin (hCG) binding or cAMP generation. Thus, it was suggested that cGMP is involved in the regulation of Leydig cell testosterone biosynthesis.

Another study using NO donors also found a biphasic effect of NO on testosterone production (Valenti et al. 1999). With low levels of NO, they observed a transient stimulatory effect that appeared to correlate with increased cGMP levels. On the contrary, high levels of NO were associated with testosterone inhibition with no change in cGMP production. Additional studies found that immobilization stress increased $\mathrm{NO}$ in rat testis with a concomitant reduction in testosterone production (Kostic et al. 1998) and that injection of an NO donor into the testis mimicked this effect (Kostic et al. 2000). Furthermore, inhibiting NOS increased testosterone production in Leydig cells (Dobashi et al. 2001).

Steroidogenesis in the testes appears to be dependent on cGMP (Andric et al. 2007), which is in marked contrast to adrenal steroid production, which has been shown to be cGMP independent (Hanke et al. 1998). Recent studies (Andric et al. 2010) have provided evidence for the role of testosterone itself in the reduction in steroidogenesis by Leydig cells through regulation of the NO-cGMP signaling cascade. Testosterone enanthate treatment of rats for 2 weeks resulted not only in decreased serum LH but reduced the ability of isolated Leydig cells to produce testosterone. This was attributed to the observed upregulation of iNOS protein and NO production.

It appears that in the testes, the inhibitory effect of $\mathrm{NO}$ is mediated, at least in part, through inhibition of the hemecontaining steroidogenic enzyme CYP17 (P450c17). When progesterone or pregnenolone was added to cultured rat Leydig cells, NO donors inhibited testosterone production (Del Punta et al. 1996, Pomerantz \& Pitelka 1998). However, NO donors did not inhibit testosterone production from exogenous dehydroepiandrosterone or androstenedione (Pomerantz \& Pitelka 1998).

At higher concentrations in vitro, NO also suppressed Leydig cell function through inhibition of CYP11A1 (Del Punta et al. 1996, Drewett et al. 2002). On the contrary, at lower concentrations, NO appeared to stimulate steroidogenesis in Leydig cells by activating soluble guanylate cyclasecGMP signaling, which appears to be through activation of cGMP-dependent protein kinase 1 (PRKG1) and phosphorylation of StAR protein (Andric et al. 2007, 2010). Interestingly, all three NOS isoforms have been identified in testes (Kim et al. 2007) and NO inhibition of testosterone synthesis is conserved across species as diverse as teleost fish (nee Pathak \& Lal 2008) and birds (Di Fiore et al. 2008).

Adrenal The early work of Palacios et al. (1989) suggested that the adrenal gland has an active NOS system and that adrenal NOS was NADPH and calcium dependent with 
inhibition by L-arginine. These studies were performed by whole rat adrenals and bovine adrenal cortical and medullary cytosol. Multiple studies later demonstrated immunohistochemical localization of nNOS in the adrenal medulla (Dun et al. 1993, Afework et al. 1994, Heym et al. 1994, Marley et al. 1995, Peterson et al. 2001, Monau et al. 2009).

Like the ovary and testes, steroidogenesis in the adrenal gland also appears to be influenced by NO. This occurs in multiple steroidogenic regions of the adrenal cortex. In adult rat zona glomerulosa, NO clearly inhibited not only basal, but also ACTH and angiotensin II-induced aldosterone production (Hanke et al. 1998). Interestingly, later studies by the same group observed that NO inhibition of aldosterone biosynthesis was cGMP independent, and reversed by the NOS inhibitor thiocitrulline (Hanke et al. 2000). In vivo studies in human subjects also showed that inhibition of NOS with L-NAME increased aldosterone levels (Muldowney et al. 2004).

At the level of the zona fasciculata, NO donors decreased both basal and ACTH-stimulated corticosterone production while NOS inhibition enhanced glucocorticoid output (Cymeryng et al. 1998). Other studies on the zona fasciculata found $\mathrm{NO}$ to act as an inhibitor of corticosterone biosynthesis (Adams et al. 1992). Together, these data suggested that NO-mediated inhibition of key rate-limiting steps in the steroidogenic pathway (Drewett et al. 2002) that will be discussed below. The results of these studies are in marked contrast to studies by Mohn et al. (2005) who found that NO enhanced corticosterone release from adrenals in vitro. They postulated that ACTH treatment activated NOS and the resulting increase in $\mathrm{NO}$-activated cyclooxygenase yielding increased $\mathrm{PGE}_{2}$ production. $\mathrm{PGE}_{2}$ in turn was hypothesized to facilitate release of corticosterone from microvesicles or other cellular organelles within the adrenal cortex. The variance of this study with those previously described has been suggested to be due to the difference in the in vitro preparation. Whereas previous studies have used dispersed cell preparations, the study by Mohn et al. (2005) utilized a preparation in which an entire half of a bisected adrenal gland was incubated intact. The authors suggested that the loss of the cell-cell interactions might be responsible for the differences in responsiveness to NO. Whether this is the case has yet to be established.

In our laboratory, we studied the effect of NO on cortisol biosynthesis using adrenal cortical cells collected from nearterm sheep fetuses under normoxic conditions as well as from fetuses that were moderately hypoxic throughout most of gestation (long-term hypoxic (LTH)). We found that enhancement of $\mathrm{NO}$ with either sodium nitroprusside or $\mathrm{L}$-arginine resulted in an inhibition of $\mathrm{ACTH}$-induced cortisol synthesis, but only in adrenocortical cells from LTH fetal adrenals. L-NAME also had an effect on the LTH group with a significant increase in cortisol compared with ACTH treatment alone. A similar trend was noted in the control but was not significant. L-NAME also counteracted the inhibitory effect of L-arginine on cortisol synthesis (Monau et al. 2010). These data clearly illustrate that NO plays a significant role in the regulation of cortisol synthesis in the LTH fetal adrenal. The interaction of NO and hypoxia on steroidogenesis will be discussed later in this review.

\section{Cellular localization of NOS in endocrine tissue}

Although the potent inhibitory effects of NO on steroidogenesis are clear, the source of $\mathrm{NO}$ in endocrine tissue is controversial. Endocrine tissues are composed of an intricate arrangement of steroidogenic cells as well as other non-steroidogenic components such as macrophages, endothelial cells, fibroblasts, and neuronal cells (Mohn et al. 2005). The short half life of NO dictates that the site and source of NO production be in close proximity to the target cells for inhibition to occur. The source of NO remains unclear but appears to be dependent on tissue type as well as species. To determine the origin of $\mathrm{NO}$, numerous studies have focused on the isolation of NOS isoforms in endocrine tissue.

In the human ovary, NOS was localized in granulosa-luteal cells by immunocytochemistry (Van Voorhis et al. 1994). Further studies using in situ hybridization localized iNOS to granulosa cells of secondary follicles and small antral follicles of the rat ovary (Van Voorhis et al. 1995). On the contrary, eNOS could only be localized in the vascular portion of the ovarian stroma and not in the granulosa cells themselves. In porcine granulosa cells both iNOS and eNOS were localized in granulosa cells (Masuda et al. 1997).

Cellular localization of NOS isoforms in the testes has been less documented. However, multiple studies using immunohistochemical methods have demonstrated the presence of NOS not only in Leydig cells but also to a lesser extent in a wide range of testicular tissue, including Sertoli, peritubular, endothelial, and macrophage cells (Zini et al. 1996, Davidoff et al. 1997). More recent studies by Lamanna et al. (2007) also utilizing immunohistochemistry demonstrated the presence of nNOS in Leydig cells of boar testes that in some cases colocalized with D-aspartic acid.

The majority of studies examining localization of NOS have focused on the adrenal gland. Early experiments found immunoreactive NOS proteins or NOS activity in acutely isolated adrenal cortical tissue (Afework et al. 1994, Marley et al. 1995). nNOS also increased in rat adrenal cortex after immobilization stress (Kishimoto et al. 1996, Natarajan et al. 1997), and eNOS expression has been shown in rat zona glomerulosa (Natarajan et al. 1997, Cymeryng et al. 2002) and fasciculata (Cymeryng et al. 2002) and in adult sheep fasciculata (Peterson et al. 2001). Hanke \& Campbell (2000), however, were unable to demonstrate the presence of NOS in cultured bovine adrenal zona glomerulosa cells by western analysis or NOS enzymatic activity. On the contrary, adrenal endothelial cells showed both enzymatic and immunoreactive eNOS. It was suggested that these disparities could be the result of species differences or cell culture conditions. However, it is clear that cortical NOS expression is regulated, since immobilization stress increased $n N O S$ 
mRNA in the adrenal cortex of rats (Natarajan et al. 1997, Cymeryng et al. 2002). It is important to note that these data were derived from the study of adult adrenal tissue.

A recent study from our laboratory utilized both qRTPCR and western blot to show that although mRNA for all three NOS isoforms were present in the ovine fetal adrenal cortex, there was no detectable protein expression for iNOS and that eNOS was the predominant isoform (Monau et al. 2009). This information was derived from a whole adrenal cortex preparation, however, and did not reveal the actual cellular localization of the eNOS. Additional studies using standard immunohistochemistry demonstrated that eNOS appeared to be localized not only within the vasculature but also in the adrenal cortical cells themselves. The intensity of immunohistochemical staining for eNOS was greatest in the zona fasciculata region of the cortex which is similar to the distribution of eNOS staining reported in the adult ovine adrenal (Peterson et al. 2001). In that study, however, staining for nNOS was not apparent. We suggested that the differences in nNOS expression between adult and fetus were due to developmental changes (Monau et al. 2009). We also demonstrated very low expression levels of iNOS mRNA, but iNOS protein was undetectable with either western analysis or immunohistochemistry. A similar lack of protein expression was noted in earlier studies of rat and human adrenal cortex (Natarajan et al. 1997), bovine zona glomerulosa cells (Hanke \& Campbell 2000), and adult ovine adrenal (Peterson et al. 2001). The absence of iNOS seems logical from a regulatory standpoint since iNOS activation is calcium independent and is only regulated at the level of expression unlike the other NOS isoforms. This would make iNOS a relatively ineffective mechanism in controlling steroidogenesis.

Further evidence for localization of eNOS within adrenal cortical cells was provided by immunofluorescent dual labeling studies. eNOS clearly colocalized with CYP17, a key enzyme involved in cortisol synthesis that is expressed in cells of the zona fasciculata (Monau et al. 2009). Together, these data further reinforce the concept that adrenal cortical cells express eNOS and that NO produced locally may play a role in local regulation of cortisol synthesis. Other studies have also suggested that endogenous generation of $\mathrm{NO}$ from adrenal cortical cells occurs through constitutively expressed eNOS in the rat (Cymeryng et al. 2002).

As described above there still remains some controversy over the exact source of $\mathrm{NO}$ in various endocrine tissues. However, irrespective of differences in species, stage of development or actual cellular localization of NOS, it is likely that steroidogenic tissues such as the ovary, testes, and adrenal are exposed to NO in response to various physiological and pathological situations.

\section{Mechanism(s) of NO disruption of steroidogenesis}

As previously described, endocrine tissues are exposed to $\mathrm{NO}$ and in general, NO has an inhibitory effect on steroidogenesis. The potential mechanisms of $\mathrm{NO}$ action will be examined in the context of both direct and potentially indirect effects.

\section{Direct effects}

Soluble guanylate cyclase and cGMP. The classic mechanism by which NO mediates cellular signaling is activation of soluble guanylate cyclase. NO activates guanylate cyclase by altering its conformation via binding to the heme group of this enzyme, leading to elevation of intracellular cGMP with subsequent activation of PKG (Ignarro 1990). This has been best studied in vascular relaxation. However, the vasorelaxant actions of $\mathrm{NO}$ are not fully blocked by inhibitors of guanylate cyclase, indicating that a significant component of NO-mediated vasorelaxation is cGMP independent (Denninger \& Marletta 1999). Indeed, many of the known effects of NO now appear to be independent of intracellular cGMP. The inhibitory effect of $\mathrm{NO}$ on steroidogenesis has also been shown to be cGMP independent in the adrenal gland (Hanke et al. 2000). The effects of NO on steroidogenesis in granulosa cells also appears to be cGMP independent since treatment with 8-bromo-cGMP did not inhibit steroid biosynthesis (Masuda et al. 1997). Later studies by Basini et al. (2000), also demonstrated that NO inhibits steroidogenesis in granulosa cells without involving cGMP.

Effects on heme binding. Similar to guanylate cyclase, NO is capable of competitively interacting with the heme oxygenbinding site of key steroidogenic enzymes such as CYP11A1 and CYP17 (Tsubaki et al. 1987). Studies using purified or semi-purified cytochrome P450 enzymes confirmed these earlier observations (Wink et al. 1993, Hanke et al. 1998). Since these enzymes use several rounds of attack of the hemeoxygen complex on the steroid substrate, Peterson et al. (2001) suggested that such multi-step targets would be more sensitive to NO inhibition than other enzymes such as CYP21 or CYP11B1. Hanke \& Campbell (2000) also clearly demonstrated the relationship between oxygen levels, NO and steroidogenesis by showing that decreasing oxygen concentrations resulted in a lower threshold for NOmediated inhibition of aldosterone synthesis in adult rat adrenals. Overall, this competitive relationship makes NO an effectual inhibitor of steroid biosynthesis.

\section{Potential indirect effects on NO}

Cysteine S-nitrosylation and tyrosine nitration. Maintaining the proper redox status of cysteine residues is critical for the structure and function of numerous enzymes, transcription factors and receptors. Free sulfhydryl groups of cysteine are subject to oxidation by reactive oxygen species (widely used as a marker for oxidative stress) as well as nitrogen species such as NO. It is becoming recognized that NO-mediated $S$-nitrosylation of reactive cysteine sulfhydryl residues is reversible and as such, an important post-translational modification regulated in a manner akin to phosphorylation. $\mathrm{NO}$ reacts with $\mathrm{O}_{2}$ to form the more reactive 
$\mathrm{NO}$-derived species including $\mathrm{NO}_{2}$ and $\mathrm{N}_{2} \mathrm{O}_{3}$ that $S$-nitrosylate cysteine thiols in target proteins. In vivo, cysteine $S$-nitrosylation is dynamically controlled, with steady-state levels regulated by rates of $\mathrm{NO}$ formation via one of the NOS isoforms versus de-nitrosylation of the targeted cysteine residues.

A large number of the physiological actions of $\mathrm{NO}$ are mediated via reversible post-translational modification of proteins critical for cellular function (Stamler et al. 2001). There are two distinct post-translational modifications of proteins mediated by $\mathrm{NO}$ and NO-derived species: $S$-nitrosylation of cysteine residues and nitration of tyrosine residues. Cysteine $S$-nitrosylation is generally considered to mediate physiological actions of NO (Stamler et al. 2001) while tyrosine nitration is most often implicated in pathological states (Greenacre \& Ischiropoulos 2001). Indeed Stamler et al. (2001) supplied a table of over 100 proteins known to be targeted by NO-mediated cysteine $S$-nitrosylation. These include key signaling proteins such as the NMDA receptor, RAS, dexRAS, SRC, JNK, and FOS/JUN (Hess et al. 2005). S-nitrosylation has also been demonstrated to inactivate protein-tyrosine phosphatases (PT-1, 2) thus prolonging signaling. In particular those downstream from tyrosine kinases, including SRC and growth factor receptors, are affected since the latter rely on their receptor tyrosine kinase activity in transducing their signal. Cysteine $S$-nitrosylation is reversible by either glutathione or thioredoxin thus representing potential rapid regulatory steps. Thioredoxin is also subject to regulation by thioredoxin interacting protein (TXNIP) that inhibits its activity (Patwari et al. 2006). TXNIP expression and activity is increased by p38 MAPK (Li et al. 2009).

Given the previous widespread demonstration of cysteine $S$-nitrosylation on protein function, $S$-nitrosylation of CYP11A and/or CYP17 is a potential mechanism by which NO could suppress steroidogenesis. CYP enzymes have critical cysteine residues in the active site and modification of these residues could play a crucial role in their activity. Indeed CYP $S$-nitrosylation has been reported in liver (Lee et al. 2008). Data from our laboratory have preliminarily confirmed S-nitrosylation of CYP17 in the fetal adrenal cortex (Ducsay \& Myers, unpublished).

Zinc-finger transcription factors, including nuclear receptors such as the estrogen receptor (Garban et al. 2005) are also targets of $S$-nitrosylation, resulting in the loss of $\mathrm{Zn}^{+}$ from the DNA-binding pocket disrupting their function as transcriptional activators (Kroncke 2001). Of particular relevance, steroidogenic factor-1 (SF-1) is a member of the $\mathrm{Zn}^{+}$finger family. SF-1 is a major transcription factor governing not only formation of the adrenal cortex but the expression of CYP11A, CYP17, CYP21, and StAR as well (Sewer \& Waterman 2003, Zhao et al. 2007). As such, $S$-nitrosylation of SF-1 could also serve as another mechanism via which expression of CYP17 and CYP11A1 could be regulated.
Effects of hypoxia on NO production and steroidogenesis Hypoxia has a wide range of effects on $\mathrm{NO}$ production (and/or expression of NOS isoforms) in different animal models and tissues. Hypoxia increases eNOS expression and NO production in microvessels in the heart of pigs (Justice et al. 2000). Our group has shown that LTH enhances eNOS expression in ovine uterine arteries (Xiao et al. 2001). On the contrary, in cerebral arteries, hypoxia reduced expression of eNOS yet increased some components of the NO/cGMP/PKG pathway, thus increasing vascular sensitivity to NO (Williams et al. 2006). Murata et al. (2001) observed a reduction in eNOS expression and function in cultured pulmonary arteries following hypoxia $\left(5 \% \mathrm{O}_{2}\right.$ for 7 days). The same group also found that hypoxia-induced pulmonary hypertension reduced NO production by impairing the interaction of eNOS with its regulatory proteins (Murata et al. 2002). Hypoxia may also have divergent effects on eNOS expression with decreased fetal eNOS expression and increased adult expression in guinea pig hearts (Thompson \& Dong 2005). Hypoxia stimulates eNOS-HSP90 interaction and activates the PI3-AKT pathway leading to eNOS phosphorylation, thus increasing NO production (Chen \& Meyrick 2004).

$5^{\prime}$ AMP-activated protein kinase (AMPK) plays a key role in the regulation of a wide range of intracellular systems and is regulated by hypoxia. With decreased oxygen there is an associated decreased oxidative phosphorylation leading to a reduction in ATP and subsequent increase in AMP, the activator of AMPK. The interaction of hypoxia and the AMPK, AKT signaling of eNOS activation was clearly demonstrated in endothelial cells. Hypoxia activated AMPK, which in turn promoted mitogen-stimulated AKT activation and angiogenesis. AKT was found to be the predominant kinase involved in eNOS phosphorylation at Ser1177 in hypoxic endothelial cells. In addition, however, direct eNOS phosphorylation by AMPK was suggested to become appreciable under conditions of prolonged hypoxia (Nagata et al. 2003). Recently, Chen et al. (2009) showed that AMPK phosphorylates eNOS at Ser633 and is a functional signal of NO bioavailability.

Hypoxia activated ERK, while administration of a NOS inhibitor prevented hypoxia-induced phosphorylation in neuronal nuclei of newborn piglets, suggesting that the hypoxia-induced ERK phosphorylation is NO mediated (Mishra et al. 2004). In endothelial cells, hypoxia also enhanced ERK phosphorylation (Zhu et al. 2003). Data from our own group showed that resting PKA activity in fetal hearts was significantly higher in LTH fetuses compared with normoxic controls (Onishi et al. 2003) and that LTH upregulated eNOS gene expression in ovine uterine arteries (Xiao et al. 2001).

Together, the studies previously described demonstrate that hypoxia can regulate NOS expression/activity. It is also clear that there is both tissue and species specificity regarding NOS expression. However, all of these studies were focused 
on non-steroidogenic tissue. In reference to hypoxia and steroid biosynthesis, Raff et al. (1989) originally showed that adrenal steroidogenesis is regulated by oxygen that was further confirmed in a more recent study (Raff \& Bruder 2006). Hanke \& Campbell (2000) confirmed the relationship between oxygen levels, NO and steroidogenesis by demonstrating that decreasing oxygen concentrations resulted in a lower threshold for NO-mediated inhibition of aldosterone synthesis in adult rat adrenals.

In our model of LTH in which pregnant sheep are exposed to high-altitude hypoxia for the duration of gestation, the fetal adrenal exhibits specific adaptive endocrine responses, which appear to be related to the regulation of NO. We recently showed that LTH upregulates fetal adrenal expression of eNOS, both mRNA and protein, and that eNOS was located in the cortisol-producing cells of the zona fasciculata (Monau et al. 2009). We postulated that the enhanced ability to produce NO under conditions of LTH prevents premature maturation of the fetal adrenal cortex that if left unchecked could result in excess cortisol production in the face of the observed elevated basal ACTH levels (Myers et al. 2005).

We also found that in the LTH adrenals, enhancement of NO with either SNP or L-arginine resulted in a significant reduction in ACTH-stimulated cortisol synthesis by adrenal cortical cells in vitro, and inhibition of NOS with L-NAME resulted in increased cortisol production compared with ACTH treatment alone. None of these effects were observed in normoxic control cells (Monau et al. 2010). Fetal adrenal cortical cells display a number of differences from adult adrenocortical cells that may account for the lack of major effects of $\mathrm{NO}$ on normoxic fetal adrenal cortical cells in vitro. Our finding that normoxic cells do not respond to NO while those from hypoxic fetuses do respond indicates an increased sensitivity to NO, or perhaps an advanced maturation of these cells to a more adult-like phenotype. Furthermore, basal NOS activity was enhanced in the LTH that is in agreement with the earlier observation that LTH adrenals had enhanced eNOS expression (Monau et al. 2009). Surprisingly, treatment with stress levels of ACTH decreased NOS activity in the LTH group.

One of the key factors that may link ACTH stimulation of cortisol production and a decrease in NOS activity is ERK1/2. Although the role of ERK1/2 on NOS expressio$\mathrm{n} /$ activity is controversial, it is apparent that it plays a role in regulating NOS activity. ERK1/2 inhibition upregulated ATP-stimulated eNOS activity but inhibited ATP-stimulated activity in COS-7 cells (Cale \& Bird 2006). MEK/ERK1/2 inhibition also enhanced eNOS activity in porcine pulmonary arteries (Chen \& Meyrick 2004). Therefore, studies suggest that stimulation of ERK1/2 could inhibit NOS activation. ERK1/2 stimulation plays an important role in adrenal steroidogenesis by upregulation of StAR expression (Gyles et al. 2001). We have recently shown that the ERK1/2 signaling pathway plays a key role in ACTH- and cAMPinduced cortisol synthesis in the ovine fetal adrenal cortical cells (Vargas et al. 2009). Furthermore, ERK inhibition had a greater effect and was more pronounced in the LTH group, consistent with our preliminary data that ERK1/2 are upregulated in response to LTH (Ducsay \& Myers, unpublished observations). Although the direct effect of $\mathrm{NO}$ on StAR activity expression is controversial (Dobashi et al. 2001, Cymeryng et al. 2002, Andric et al. 2007), this is another potential pathway of interaction of $\mathrm{NO}$, and fetal adrenal steroidogenesis. ACTH has also been shown to inhibit iNOS mRNA in macrophages (Altavilla et al. 2000).

In our study, the locus of the ACTH effect on NOS activity in the LTH was not established (Monau et al. 2010). However, together with the data showing significant inhibition of cortisol output with NO stimulation and enhanced cortisol output in response to NOS inhibition, it appears that this may be a mechanism(s) of regulating cortisol responses under conditions of LTH. In vivo under basal conditions, despite higher basal levels of ACTH, LTH fetuses maintain plasma cortisol concentrations at a level similar to normoxic controls. The previously described upregulation of adrenal eNOS in the LTH group may be responsible for enhanced basal NOS activity. This would exert an inhibitory effect on basal cortisol production overcoming the low level of stimulation by elevated basal ACTH. Stimulation with high levels of ACTH in vitro (Monau et al. 2010) or those observed in vivo in response to a secondary stressor (Adachi et al. 2004, Imamura et al. 2004) would decrease NO activity, thus enhancing cortisol output. We propose that this can occur through ACTH interaction with the MEK/ERK1/2 and/or the $\mathrm{AKT} / \mathrm{IP}_{3}$. A preliminary investigation of expression of both the native and phosphorylated forms of these members of their respective signaling pathways revealed that there is an enhancement of protein expression following LTH. Phosphorylation of SF-1, the major transcription factor governing CYP11A1 and CYP17 expression is also enhanced (Ducsay \& Myers, unpublished observations).

Another mechanism activating eNOS is the interaction with CAV-1 and HSP90. Gratton et al. (2000)) showed that eNOS interacts with both CAV-1 and HSP90 during activation/inactivation translocation cycle, binding in a trimeric complex. CAV-1 keeps eNOS in an inactive state at the caveolae while also inhibiting eNOS translocation and/ or the stimulatory effect of calmodulin binding. On the contrary, HSP90 not only binds free eNOS but may also disrupt the CAV-1/eNOS complex. Furthermore, hypoxia has been shown to alter CAV-1 expression and increase HSP90 binding to eNOS (Shi et al. 2002, Chen \& Meyrick 2004). Our studies on the effects of LTH on CAV-1 and HSP90 showed that in the LTH fetal adrenal cortex, higher levels of mRNA and density of HSP90 and lower levels of CAV-1 correlated with our previously observed difference in eNOS expression and activity. These data support the hypothesis that LTH alters the distribution and expression of HSP90 and CAV-1 in the ovine adrenal and suggest that these proteins play a regulatory role in eNOS activity in the LTH fetal adrenal (Furuta et al. 2010). 
Consistent with the known effects of hypoxia reported in literature and our published and preliminary data in the fetal adrenal cortex of the LTH sheep fetus, we propose that LTH results in increased activation of PI3K, AMPK, and RAS signaling pathways. Activation of PI3K and/or AMPK results in elevated $\mathrm{pAKT} / \mathrm{AKT}$ which we hypothesize results in increased activity of $\mathrm{eNOS}$ via phosphorylation of eNOS at Ser1179 and dissociation of CAV-1 and recruitment of the eNOS activator, HSP90. Activated eNOS results in NO generation leading to Cys $S$-nitrosylation of critical target proteins governing cortisol synthesis (CYP11A1 and CYP17), SF-1, which regulates CYP11A1 and CYP17 transcription. We hypothesize that $S$-nitrosylation of cysteine residues in the DNA-binding domain of SF-1 reduces its capacity to interact with specific SF-1 cis elements in the promoter regions of CYP17 and CYP11A1 while nitrosylation of CYP11A1 and CYP17 decreases enzymatic activity. These hypotheses are consistent with the decreased cortisol synthesis and CYP expression observed in the adrenal cortex of LTH fetal sheep in spite of elevated basal plasma ACTH. However, under conditions of a secondary stressor, large increases in ACTH (approximately 10- to 20-fold over basal levels) override the inhibitory effects of $\mathrm{NO}$ and result in enhanced cortisol production compared with that observed in control adrenals. Together, our hypotheses for the role of $\mathrm{NO}$ in the regulation of adrenal cortisol synthesis under hypoxic conditions are summarized in Fig. 1.

In addition to the schema outlined in Fig. 1, another novel mechanism involved in hypoxic regulation of NO-induced regulation of steroidogenesis is leptin. Leptin has been shown to enhance eNOS activity in a number of tissues (Mehebik et al. 2005, Fruhbeck 2006, Procopio et al. 2009) and also appears to be a hypoxia-inducible gene (Tschop et al. 1998, Ip et al. 2000, Tschop et al. 2000). Although we have shown that the LTH fetal adrenal has enhanced eNOS expression (Monau et al. 2009), the mechanism responsible for the upregulation of eNOS with its subsequent inhibitory effects of cortisol biosynthesis remains undefined. We have shown that under conditions of LTH, leptin also appears to be a hypoxia-inducible gene in the ovine fetus with enhanced expression of leptin in fetal adipose tissue and increased plasma leptin levels (Ducsay et al. 2006). Elevations in leptin in response to hypoxia could therefore also play a role in upregulation of $\mathrm{NO}$ in steroidogenic tissues.

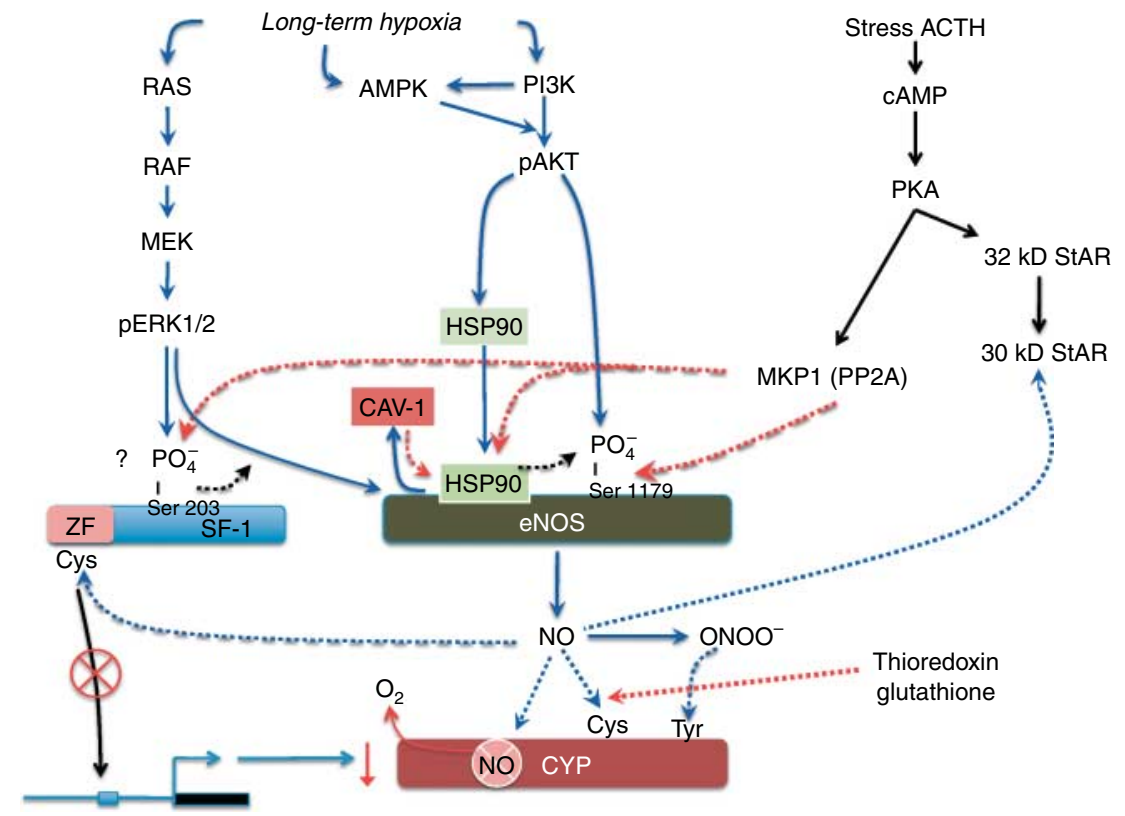

Figure 1 Proposed model for mechanism(s) via which development under sustained moderate hypoxia (long-term hypoxia (LTH)) attenuates adrenocortical glucocorticoid production despite elevated plasma ACTH. We propose that LTH activates eNOS via the PI3K, AMPK signaling pathways. AKT has been demonstrated to activate eNOS via phosphorylation of Ser1179. AKT also targets HSP90 resulting in its association with eNOS (and accompanying dissociation of CAV-1 from eNOS) resulting in cellular translocation of eNOS and enhancing eNOS activity. Activated eNOS results in NO generation and potentially peroxinitrite formation leading to cysteine nitrosylation (and potentially, tyrosine nitration) of rate limiting $\mathrm{P}_{450}$ enzymes governing cortisol synthesis (CYP11A1 and CYP17). NO has also been shown to displace oxygen in the heme group of heme-containing proteins, such as P450 enzymes, inhibiting their activity. SF-1, a key zinc-finger transcription factor regulating $\mathrm{CYP} 11 \mathrm{~A} 1$ and $\mathrm{CYP} 17$ transcription, is a potential target for cysteine nitrosylation which could contribute to the lowered expression of CYP11A1 and CYP17 reported in the LTH adrenal cortex. In addition, long-term hypoxia activation of the RAS signaling pathway, via ERK1/2 activation may alter SF-1 function via phosphorylation of this transcription factor as well as affecting eNOS activity. Stress-induced elevation in ACTH may overcome the NO inhibition of steroidogenesis via induction of protein phosphatases as well as by increasing levels of thioredoxin or glutathione resulting in de-nitrosylation. 


\section{Conclusions}

In summary, independent work from numerous laboratories on a wide variety of species supports the concept that NO exerts powerful, physiological, effects on steroidogenesis in key endocrine tissues such as the ovary, testes, and adrenal gland. Despite the general agreement of a role for $\mathrm{NO}$ in modulating steroidogenesis, the mechanisms via which $\mathrm{NO}$ regulates steroidogenesis may be tissue, and perhaps situation specific. The cell type specificity observed between adrenal cortex and gonads may also reflect differences in NO mechanisms. For example, direct effects on the enzyme via heme binding versus those mediated by cysteine or tyrosine nitration or upstream actions on other signaling cascades that mediate steroidogenesis. However, the noted actions may also reflect differences in culture conditions, age of cells (fetal versus adult), species, etc.

As hypothesized by Repetto et al. (2006) NO may serve as an autocrine/paracrine modulator of steroidogenesis involved in the refinement of the cellular responses to hormones. Such fine-tuning would provide a mechanism for the endocrine tissue to avoid an 'all or none' type of response. For example, in the ovary, NO regulation of blood flow may provide a key means of altering steroid formation, while in the adrenal gland, NO may alter steroid production by acting directly on the steroidogenic enzymes themselves or altering their expression via effects on transcription factor function. Studies from our laboratory and others supports that hypoxia modulation of steroidogenesis is profound and appears to enhance the effect of $\mathrm{NO}$ on steroidogenesis as well as upregulating expression of eNOS. In the oxygen compromised fetus, NO may provide a key potential mechanism for maintaining normal cortisol levels to allow for continued fetal growth and development in the face of this adverse situation and may implicate the NO system as a key target for treatment of preterm or compromised neonates in the neonatal intensive care unit.

\section{Declaration of interest}

The authors declare that there is no conflict of interest that could be perceived as prejudicing the impartiality of the review reported.

\section{Funding}

This work was supported by NIH grants PO1HD31226 and R01HD51951.

\section{References}

Adachi K, Umezaki H, Kaushal KM \& Ducsay CA 2004 Long-term hypoxia alters ovine fetal endocrine and physiological responses to hypotension. American Journal of Physiology. Regulatory, Integrative and Comparative Physiology 287 R209-R217. (doi:10.1152/ajpregu. $00701.2003)$
Adams ML, Nock B, Truong R \& Cicero TJ 1992 Nitric oxide control of steroidogenesis: endocrine effects of NG-nitro-L-arginine and comparisons to alcohol. Life Sciences 50 PL35-PL40. (doi:10.1016/0024-3205(92) 90384-2)

Afework M, Tomlinson A \& Burnstock G 1994 Distribution and colocalization of nitric oxide synthase and NADPH-diaphorase in adrenal gland of developing, adult and aging Sprague-Dawley rats. Cell and Tissue Research 276 133-141. (doi:10.1007/BF00354792)

Altavilla D, Bazzani C, Squadrito F, Cainazzo MM, Mioni C, Bertolini A \& Guarini S 2000 Adrenocorticotropin inhibits nitric oxide synthase II mRNA expression in rat macrophages. Life Sciences 66 2247-2254. (doi:10.1016/S0024-3205(00)00553-1)

Andric SA, Janjic MM, Stojkov NJ \& Kostic TS 2007 Protein kinase G-mediated stimulation of basal Leydig cell steroidogenesis. American Journal of Physiology. Endocrinology and Metabolism 293 E1399-E1408. (doi:10.1152/ajpendo.00482.2007)

Andric SA, Janjic MM, Stojkov NJ \& Kostic TS 2010 Testosterone-induced modulation of nitric oxide-cGMP signaling pathway and androgenesis in the rat Leydig cells. Biology of Reproduction 83 434-442. (doi:10.1095/ biolreprod.110.083626)

Arakane F, King SR, Du Y, Kallen CB, Walsh LP, Watari H, Stocco DM \& Strauss JF III 1997 Phosphorylation of steroidogenic acute regulatory protein (StAR) modulates its steroidogenic activity. Journal of Biological Chemistry 272 32656-32662. (doi:10.1074/jbc.272.51.32656)

Basini G, Grasselli F, Ponderato N, Bussolati S \& Tamanini C 2000 Lipid hydroperoxide and cGMP are not involved in nitric oxide inhibition of steroidogenesis in bovine granulosa cells. Reproduction, Fertility, and Development 12 289-295. (doi:10.1071/RD00089)

Cale JM \& Bird IM 2006 Inhibition of MEK/ERK1/2 signalling alters endothelial nitric oxide synthase activity in an agonist-dependent manner. Biochemical Journal 398 279-288. (doi:10.1042/BJ20060371)

Chen JX \& Meyrick B 2004 Hypoxia increases Hsp90 binding to eNOS via PI3K-Akt in porcine coronary artery endothelium. Laboratory investigation; a Journal of Technical Methods and Pathology 84 182-190. (doi:10.1038/ labinvest.3700027)

Chen Z, Peng IC, Sun W, Su MI, Hsu PH, Fu Y, Zhu Y, DeFea K, Pan S, Tsai MD et al. 2009 AMP-activated protein kinase functionally phosphorylates endothelial nitric oxide synthase Ser633. Circulation Research 104 496-505. (doi:10.1161/CIRCRESAHA.108.187567)

Cymeryng CB, Dada LA \& Podesta EJ 1998 Effect of nitric oxide on rat adrenal zona fasciculata steroidogenesis. Journal of Endocrinology 158 197-203. (doi:10.1677/joe.0.1580197)

Cymeryng CB, Lotito SP, Colonna C, Finkielstein C, Pomeraniec Y, Grion N, Gadda L, Maloberti P \& Podesta EJ 2002 Expression of nitric oxide synthases in rat adrenal zona fasciculata cells. Endocrinology 143 1235-1242. (doi:10.1210/en.143.4.1235)

Daff S 2010 NO synthase: structures and mechanisms. Nitric Oxide 23 1-11. (doi:10.1016/j.niox.2010.03.001)

Davidoff MS, Middendorff R, Mayer B, deVente J, Koesling D \& Holstein AF 1997 Nitric oxide/cGMP pathway components in the Leydig cells of the human testis. Cell and Tissue Research 287 161-170. (doi:10.1007/ s004410050742)

Dees WL, Dissen GA, Hiney JK, Lara F \& Ojeda SR 2000 Alcohol ingestion inhibits the increased secretion of puberty-related hormones in the developing female rhesus monkey. Endocrinology 141 1325-1331. (doi:10.1210/en.141.4.1325)

Del Punta K, Charreau EH \& Pignataro OP 1996 Nitric oxide inhibits Leydig cell steroidogenesis. Endocrinology 137 5337-5343. (doi:10.1210/en.137.12. 5337)

Denninger JW \& Marletta MA 1999 Guanylate cyclase and the NO/cGMP signaling pathway. Biochimica et Biophysica Acta 1411 334-350. (doi:10.1016/S0005-2728(99)00024-9)

Di Fiore MM, Lamanna C, Assisi L \& Botte V 2008 Opposing effects of $\mathrm{D}$-aspartic acid and nitric oxide on tuning of testosterone production in mallard testis during the reproductive cycle. Reproductive Biology and Endocrinology 6 28. (doi:10.1186/1477-7827-6-28)

Dobashi M, Fujisawa M, Yamazaki T, Okuda Y, Kanzaki M, Tatsumi N, Tsuji T, Okada H \& Kamidono S 2001 Inhibition of steroidogenesis in 
Leydig cells by exogenous nitric oxide occurs independently of steroidogenic acute regulatory protein (star) mRNA. Archives of Andrology 47 203-209. (doi:10.1080/014850101753145915)

Drewett JG, Adams-Hays RL, Ho BY \& Hegge DJ 2002 Nitric oxide potently inhibits the rate-limiting enzymatic step in steroidogenesis. Molecular and Cellular Endocrinology 194 39-50. (doi:10.1016/S03037207(02)00214-9)

Ducsay CA, Hyatt K, Mlynarczyk M, Kaushal KM \& Myers DA 2006 Long-term hypoxia increases leptin receptors and plasma leptin concentrations in the late-gestation ovine fetus. American Journal of Physiology. Regulatory, Integrative and Comparative Physiology 291 R1406-R1413. (doi:10.1152/ajpregu.00077.2006)

Dun NJ, Dun SL, Wu SY \& Forstermann U 1993 Nitric oxide synthase immunoreactivity in rat superior cervical ganglia and adrenal glands. Neuroscience Letters 158 51-54. (doi:10.1016/0304-3940(93)90610-W)

Faes MR, Caldas-Bussiere MC, Viana KS, Dias BL, Costa FR \& Escocard RM 2009 Nitric oxide regulates steroid synthesis by bovine antral granulosa cells in a chemically defined medium. Animal Reproduction Science 110 222-236. (doi:10.1016/j.anireprosci.2008.01.018)

Fruhbeck G 2006 Intracellular signalling pathways activated by leptin. Biochemical Journal 393 7-20. (doi:10.1042/BJ20051578)

Furuta K, Johnson CB, Myers DA \& Ducsay CA 2010 Long-term hypoxia alters expression and distribution of heat shock protein 90 and caveolin- 1 in the ovine fetal adrenal. Reproductive Sciences 17 295-296A.

Garban HJ, Marquez-Garban DC, Pietras RJ \& Ignarro LJ 2005 Rapid nitric oxide-mediated $S$-nitrosylation of estrogen receptor: regulation of estrogen-dependent gene transcription. PNAS 102 2632-2636. (doi:10.1073/pnas.0409854102)

Gobbetti A, Boiti C, Canali C \& Zerani M 1999 Nitric oxide synthase acutely regulates progesterone production by in vitro cultured rabbit corpora lutea. Journal of Endocrinology 160 275-283. (doi:10.1677/joe.0.1600275)

Gratton JP, Fontana J, O'Connor DS, Garcia-Cardena G, McCabe TJ \& Sessa WC 2000 Reconstitution of an endothelial nitric-oxide synthase (eNOS), hsp90, and caveolin-1 complex in vitro. Evidence that hsp90 facilitates calmodulin stimulated displacement of eNOS from caveolin-1. Journal of Biological Chemistry 275 22268-22272. (doi:10.1074/jbc. M001644200)

Greenacre SA \& Ischiropoulos H 2001 Tyrosine nitration: localisation, quantification, consequences for protein function and signal transduction. Free Radical Research 34 541-581. (doi:10.1080/ 10715760100300471)

Gyles SL, Burns CJ, Whitehouse BJ, Sugden D, Marsh PJ, Persaud SJ \& Jones PM 2001 ERKs regulate cyclic AMP-induced steroid synthesis through transcription of the steroidogenic acute regulatory (StAR) gene. Journal of Biological Chemistry 276 34888-34895. (doi:10.1074/jbc. M102063200)

Hanke CJ \& Campbell WB 2000 Endothelial cell nitric oxide inhibits aldosterone synthesis in zona glomerulosa cells: modulation by oxygen. American Journal of Physiology. Endocrinology and Metabolism 279 E846-E854.

Hanke CJ, Drewett JG, Myers CR \& Campbell WB 1998 Nitric oxide inhibits aldosterone synthesis by a guanylyl cyclase-independent effect. Endocrinology 139 4053-4060. (doi:10.1210/en.139.10.4053)

Hanke CJ, O'Brien T, Pritchard KA Jr \& Campbell WB 2000 Inhibition of adrenal cell aldosterone synthesis by endogenous nitric oxide release. Hypertension 35 324-328. (doi:10.1161/01.HYP.35.1.324)

Hess DT, Matsumoto A, Kim SO, Marshall HE \& Stamler JS 2005 Protein $S$-nitrosylation: purview and parameters. Nature Reviews. Molecular Cell Biology 6 150-166. (doi:10.1038/nrm1569)

Heym C, Colombo-Benckmann M \& Mayer B 1994 Immunohistochemical demonstration of the synthesis enzyme for nitric oxide and of comediators in neurons and chromaffin cells of the human adrenal medulla. Annals of Anatomy 176 11-16.

Ignarro LJ 1990 Biosynthesis and metabolism of endothelium-derived nitric oxide. Annual Review of Pharmacology and Toxicology 30 535-560. (doi:10. 1146/annurev.pa.30.040190.002535)
Ignarro LJ 2002 Nitric oxide as a unique signaling molecule in the vascular system: a historical overview. Journal of Physiology and Pharmacology $\mathbf{5 3}$ 503-514.

Imamura T, Umezaki H, Kaushal KM \& Ducsay CA 2004 Long-term hypoxia alters endocrine and physiologic responses to umbilical cord occlusion in the ovine fetus. Journal of the Society for Gynecologic Investigation 11 131-140. (doi:10.1016/j.jsgi.2003.09.006)

Ip MS, Lam KS, Ho C, Tsang KW \& Lam W 2000 Serum leptin and vascular risk factors in obstructive sleep apnea. Chest 118 580-586. (doi:10.1378/ chest.118.3.580)

Jablonka-Shariff A \& Olson LM 1997 Hormonal regulation of nitric oxide synthases and their cell-specific expression during follicular development in the rat ovary. Endocrinology 138 460-468. (doi:10.1210/ en.138.1.460)

Justice JM, Tanner MA \& Myers PR 2000 Endothelial cell regulation of nitric oxide production during hypoxia in coronary microvessels and epicardial arteries. Journal of Cellular Physiology 182 359-365. (doi:10.1002/ (SICI) 1097-4652(200003)182:3 <359::AID-JCP6>3.0.CO;2-3)

Kim HC, Byun JS, Lee TK, Jeong CW, Ahn M \& Shin T 2007 Expression of nitric oxide synthase isoforms in the testes of pigs. Anatomia, Histologia, Embryologia 36 135-138. (doi:10.1111/j.1439-0264.2006.00739.x)

Kishimoto J, Tsuchiya T, Emson PC \& Nakayama Y 1996 Immobilizationinduced stress activates neuronal nitric oxide synthase (nNOS) mRNA and protein in hypothalamic-pituitary-adrenal axis in rats. Brain Research $\mathbf{7 2 0}$ 159-171. (doi:10.1016/0006-8993(96)00101-1)

Kostic T, Andric S, Kovacevic R \& Maric D 1998 The involvement of nitric oxide in stress-impaired testicular steroidogenesis. European Journal of Pharmacology 346 267-273. (doi:10.1016/S0014-2999(98)00057-0)

Kostic TS, Andric SA, Maric D \& Kovacevic RZ 2000 Inhibitory effects of stress-activated nitric oxide on antioxidant enzymes and testicular steroidogenesis. Journal of Steroid Biochemistry and Molecular Biology $\mathbf{7 5}$ 299-306. (doi:10.1016/S0960-0760(00)00185-0)

Kroncke KD 2001 Zinc finger proteins as molecular targets for nitric oxidemediated gene regulation. Antioxidants and Redox Signaling 3 565-575. (doi:10.1089/15230860152542934)

Lamanna C, Assisi L, Vittoria A, Botte V \& Di Fiore MM 2007 D-Aspartic acid and nitric oxide as regulators of androgen production in boar testis. Theriogenology 67 249-254. (doi:10.1016/j.theriogenology.2006.07.016)

Lee CM, Kim BY, Li L \& Morgan ET 2008 Nitric oxide-dependent proteasomal degradation of cytochrome $\mathrm{P} 4502 \mathrm{~B}$ proteins. Journal of Biological Chemistry 283 889-898. (doi:10.1074/jbc.M708821200)

Li X, Rong Y, Zhang M, Wang XL, LeMaire SA, Coselli JS, Zhang Y \& Shen YH 2009 Up-regulation of thioredoxin interacting protein (Txnip) by p38 MAPK and FOXO1 contributes to the impaired thioredoxin activity and increased ROS in glucose-treated endothelial cells. Biochemical and Biophysical Research Communications 381 660-665. (doi:10.1016/j.bbrc.2009.02.132)

Marley PD, McLeod J, Anderson C \& Thomson KA 1995 Nerves containing nitric oxide synthase and their possible function in the control of catecholamine secretion in the bovine adrenal medulla. Journal of the Autonomic Nervous System 54 184-194. (doi:10.1016/ 0165-1838(95)00013-N)

Masuda M, Kubota T, Karnada S \& Aso T 1997 Nitric oxide inhibits steroidogenesis in cultured porcine granulosa cells. Molecular Human Reproduction 3 285-292. (doi:10.1093/molehr/3.4.285)

Masuda M, Kubota T \& Aso T 2001 Effects of nitric oxide on steroidogenesis in porcine granulosa cells during different stages of follicular development. European Journal of Endocrinology/European Federation of Endocrine Societies 144 303-308.

Mehebik N, Jaubert AM, Sabourault D, Giudicelli Y \& Ribiere C 2005 Leptin-induced nitric oxide production in white adipocytes is mediated through PKA and MAP kinase activation. American Journal of Physiology. Cell Physiology 289 C379-C387. (doi:10.1152/ajpcell.00320.2004)

Michel T \& Feron O 1997 Nitric oxide synthases: which, where, how, and why? Journal of Clinical Investigation 100 2146-2152. (doi:10.1172/ JCI119750) 
Mishra OP, Zubrow AB \& Ashraf QM 2004 Nitric oxide-mediated activation of extracellular signal-regulated kinase (erk) and $\mathrm{C}$-jun $\mathrm{N}$-terminal kinase (jnk) during hypoxia in cerebral cortical nuclei of newborn piglets. Neuroscience 123 179-186. (doi:10.1016/j.neuroscience.2003.08.008)

Mohn CE, Fernandez-Solari J, De Laurentiis A, Prestifilippo JP, de la Cal C, Funk R, Bornstein SR, McCann SM \& Rettori V 2005 The rapid release of corticosterone from the adrenal induced by ACTH is mediated by nitric oxide acting by prostaglandin $\mathrm{E}_{2}$. PNAS 102 6213-6218. (doi:10.1073/ pnas.0502136102)

Monau TR, Vargas VE, King N, Yellon SM, Myers DA \& Ducsay CA 2009 Long-term hypoxia increases endothelial nitric oxide synthase expression in the ovine fetal adrenal. Reproductive Sciences 16 865-874. (doi:10.1177/ 1933719109336678)

Monau TR, Vargas VE, Zhang L, Myers DA \& Ducsay CA 2010 Nitric oxide inhibits ACTH-induced cortisol production in near-term, long-term hypoxic ovine fetal adrenocortical cells. Reproductive Sciences 17 955-962. (doi:10.1177/1933719110376092)

Moncada S \& Palmer RM 1991 Biosynthesis and actions of nitric oxide. Seminars in Perinatology 15 16-19.

Moncada S, Palmer RM \& Higgs EA 1991 Nitric oxide: physiology, pathophysiology, and pharmacology. Pharmacological Reviews 43 109-142.

Muldowney JA III, Davis SN, Vaughan DE \& Brown NJ 2004 NO synthase inhibition increases aldosterone in humans. Hypertension 44 739-745. (doi:10.1161/01.HYP.0000143852.48258.f1)

Murata T, Yamawaki H, Hori M, Sato K, Ozaki H \& Karaki H 2001 Hypoxia impairs endothelium-dependent relaxation in organ cultured pulmonary artery. European Journal of Pharmacology 421 45-53. (doi:10.1016/S00142999(01)01015-9)

Murata T, Sato K, Hori M, Ozaki H \& Karaki H 2002 Decreased endothelial nitric-oxide synthase (eNOS) activity resulting from abnormal interaction between eNOS and its regulatory proteins in hypoxia-induced pulmonary hypertension. Journal of Biological Chemistry 277 44085-44092. (doi:10. 1074/jbc.M205934200)

Myers DA, Bell PA, Hyatt K, Mlynarczyk M \& Ducsay CA 2005 Long-term hypoxia enhances proopiomelanocortin processing in the near-term ovine fetus. American Journal of Physiology. Regulatory, Integrative and Comparative Physiology 288 R1178-R1184. (doi:10.1152/ajpregu.00697.2004)

Nagata D, Mogi M \& Walsh K 2003 AMP-activated protein kinase (AMPK) signaling in endothelial cells is essential for angiogenesis in response to hypoxic stress. Journal of Biological Chemistry 278 31000-31006. (doi:10.1074/jbc.M300643200)

Natarajan R, Lanting L, Bai W, Bravo EL \& Nadler J 1997 The role of nitric oxide in the regulation of aldosterone synthesis by adrenal glomerulosa cells. Journal of Steroid Biochemistry and Molecular Biology 61 47-53. (doi:10.1016/ S0960-0760(97)00004-6)

Onishi J, Kamitomo M, Stiffel VM \& Gilbert RD 2003 Effects of long-term high-altitude hypoxia on myocardial protein kinase A activity and troponin I isoforms in fetal and nonpregnant sheep. Journal of the Society for Gynecologic Investigation 10 189-193. (doi:10.1016/S1071-5576(03)00042-X)

Palacios M, Knowles RG, Palmer RM \& Moncada S 1989 Nitric oxide from L-arginine stimulates the soluble guanylate cyclase in adrenal glands. Biochemical and Biophysical Research Communications 165 802-809. (doi:10. 1016/S0006-291X(89)80037-3)

nee Pathak ND \& Lal B 2008 Nitric oxide: an autocrine regulator of Leydig cell steroidogenesis in the Asian catfish, Clarias batrachus. General and Comparative Endocrinology 158 161-167. (doi:10.1016/j.ygcen.2008.06.009)

Patwari P, Higgins LJ, Chutkow WA, Yoshioka J \& Lee RT 2006 The interaction of thioredoxin with Txnip. Evidence for formation of a mixed disulfide by disulfide exchange. Journal of Biological Chemistry 281 21884-21891. (doi:10.1074/jbc.M600427200)

Peterson JK, Moran F, Conley AJ \& Bird IM 2001 Zonal expression of endothelial nitric oxide synthase in sheep and rhesus adrenal cortex. Endocrinology 142 5351-5363. (doi:10.1210/en.142.12.5351)

Pomerantz DK \& Pitelka V 1998 Nitric oxide is a mediator of the inhibitory effect of activated macrophages on production of androgen by the Leydig cell of the mouse. Endocrinology 139 922-931. (doi:10.1210/en.139.3.922)
Pon LA, Hartigan JA \& Orme-Johnson NR 1986 Acute ACTH regulation of adrenal corticosteroid biosynthesis. Rapid accumulation of a phosphoprotein. Journal of Biological Chemistry 261 13309-13316.

Procopio C, Andreozzi F, Laratta E, Cassese A, Beguinot F, Arturi F, Hribal ML, Perticone F \& Sesti G 2009 Leptin-stimulated endothelial nitric-oxide synthase via an AMPK/Akt signalling pathway is attenuated by interaction with C reactive protein. Endocrinology 150 3584-3593. (doi:10.1210/en.2008-0921)

Raff H \& Bruder ED 2006 Steroidogenesis in human aldosterone-secreting adenomas and adrenal hyperplasias: effects of hypoxia in vitro. American Journal of Physiology. Endocrinology and Metabolism 290 E199-E203. (doi:10.1152/ajpendo.00337.2005)

Raff H, Ball DL \& Goodfriend TL 1989 Low oxygen selectively inhibits aldosterone secretion from bovine adrenocortical cells in vitro. American Journal of Physiology. Endocrinology and Metabolism 256 E640-E644.

Repetto EM, Pannunzio V, Astort F, Martinez Calejman C, Moreno MB, Pignataro OP \& Cymeryng CB 2006 Characterization of L-arginine transport in adrenal cells: effect of ACTH. American Journal of Physiology. Endocrinology and Metabolism 291 E291-E297. (doi:10.1152/ajpendo.00413.2005)

Sewer MB \& Waterman MR 2003 ACTH modulation of transcription factors responsible for steroid hydroxylase gene expression in the adrenal cortex. Microscopy Research and Technique 61 300-307. (doi:10.1002/jemt.10339)

Shi Y, Baker JE, Zhang C, Tweddell JS, Su J \& Pritchard KA Jr 2002 Chronic hypoxia increases endothelial nitric oxide synthase generation of nitric oxide by increasing heat shock protein 90 association and serine phosphorylation. Circulation Research 91 300-306. (doi:10.1161/01.RES. 0000031799.12850.1E)

Srivastava VK, Dissen GA, Ojeda SR, Hiney JK, Pine MD \& Dees WL 2007 Effects of alcohol on intraovarian nitric oxide synthase and steroidogenic acute regulatory protein in the prepubertal female rhesus monkey. Journal of Studies on Alcohol and Drugs 68 182-191.

Stamler JS, Lamas S \& Fang FC 2001 Nitrosylation. The prototypic redox-based signaling mechanism. Cell 106 675-683. (doi:10.1016/ S0092-8674(01)00495-0)

Stocco DM 2001 StAR protein and the regulation of steroid hormone biosynthesis. Annual Review of Physiology 63 193-213. (doi:10.1146/ annurev.physiol.63.1.193)

Thompson LP \& Dong Y 2005 Chronic hypoxia decreases endothelial nitric oxide synthase protein expression in fetal guinea pig hearts. Journal of the Society for Gynecologic Investigation 12 388-395. (doi:10.1016/j.jsgi.2005.04.011)

Tschop M, Strasburger CJ, Hartmann G, Biollaz J \& Bartsch P 1998 Raised leptin concentrations at high altitude associated with loss of appetite. Lancet 352 1119-1120. (doi:10.1016/S0140-6736(05)79760-9)

Tschop M, Strasburger CJ, Topfer M, Hautmann H, Riepl R, Fischer R, Hartmann G, Morrison K, Appenzeller M, Hildebrandt W et al. 2000 Influence of hypobaric hypoxia on leptin levels in men. International Journal of Obesity and Related Metabolic Disorders 24 (Supplement 1) S151.

Tsubaki M, Hiwatashi A, Ichikawa Y \& Hori H 1987 Electron paramagnetic resonance study of ferrous cytochrome P-450scc-nitric oxide complexes: effects of cholesterol and its analogues. Biochemistry 26 4527-4534. (doi:10.1021/bi00388a054)

Valenti S, Cuttica CM, Fazzuoli L, Giordano G \& Giusti M 1999 Biphasic effect of nitric oxide on testosterone and cyclic GMP production by purified rat Leydig cells cultured in vitro. International Journal of Andrology 22 336-341. (doi:10.1046/j.1365-2605.1999.00189.x)

Van Voorhis BJ, Dunn MS, Snyder GD \& Weiner CP 1994 Nitric oxide: an autocrine regulator of human granulosa-luteal cell steroidogenesis. Endocrinology 135 1799-1806. (doi:10.1210/en.135.5.1799)

Van Voorhis BJ, Moore K, Strijbos PJ, Nelson S, Baylis SA, Grzybicki D \& Weiner CP 1995 Expression and localization of inducible and endothelial nitric oxide synthase in the rat ovary. Effects of gonadotropin stimulation in vivo. Journal of Clinical Investigation 96 2719-2726. (doi:10.1172/ JCI118339)

Vargas VE, Myers DA, Kaushal KM \& Ducsay CA 2009 ACTH induced cortisol synthesis in ovine fetal adrenocortical cells is mediated in part by extracellular signal regulated kinase (ERK) 1 and 2: effect of long term hypoxia (LTH). Reproductive Sciences $16250 \mathrm{~A}$. 
Welch C, Watson ME, Poth M, Hong T \& Francis GL 1995 Evidence to suggest nitric oxide is an interstitial regulator of Leydig cell steroidogenesis. Metabolism: Clinical and Experimental 44 234-238. (doi:10.1016/00260495(95)90271-6)

Williams JM, White CR, Chang MM, Injeti ER, Zhang L \& Pearce WJ 2006 Chronic hypoxic decreases in soluble guanylate cyclase protein and enzyme activity are age dependent in fetal and adult ovine carotid arteries. Journal of Applied Physiology 100 1857-1866. (doi:10.1152/ japplphysiol.00662.2005)

Wink DA, Darbyshire JF, Nims RW, Saavedra JE \& Ford PC 1993 Reactions of the bioregulatory agent nitric oxide in oxygenated aqueous media: determination of the kinetics for oxidation and nitrosation by intermediates generated in the $\mathrm{NO} / \mathrm{O}_{2}$ reaction. Chemical Research in Toxicology 6 23-27. (doi:10.1021/tx00031a003)

Xiao D, Bird IM, Magness RR, Longo LD \& Zhang L 2001 Upregulation of eNOS in pregnant ovine uterine arteries by chronic hypoxia. American Journal of Physiology. Heart and Circulatory Physiology 280 H812-H820.

Yamauchi J, Miyazaki T, Iwasaki S, Kishi I, Kuroshima M, Tei C \&

Yoshimura Y 1997 Effects of nitric oxide on ovulation and ovarian steroidogenesis and prostaglandin production in the rabbit. Endocrinology 138 3630-3637. (doi:10.1210/en.138.9.3630)
Zhao H, Li Z, Cooney AJ \& Lan ZJ 2007 Orphan nuclear receptor function in the ovary. Frontiers in Bioscience 12 3398-3405. (doi:10.2741/ 2321)

Zhu Y, Sun Y, Xie L, Jin K, Sheibani N \& Greenberg DA 2003 Hypoxic induction of endoglin via mitogen-activated protein kinases in mouse brain microvascular endothelial cells. Stroke 34 2483-2488. (doi:10.1161/01. STR.0000088644.60368.ED)

Zini A, O’Bryan MK, Magid MS \& Schlegel PN 1996 Immunohistochemical localization of endothelial nitric oxide synthase in human testis, epididymis, and vas deferens suggests a possible role for nitric oxide in spermatogenesis, sperm maturation, and programmed cell death. Biology of Reproduction $\mathbf{5 5}$ 935-941. (doi:10.1095/biolreprod55.5.935)

Received in final form 22 April 2011

Accepted 8 June 2011

Made available online as an Accepted Preprint 8 June 2011 